\title{
The ambition of the European Respiratory Journal: chapter 3
}

\author{
Marc Humbert ${ }^{1}$, Anh Tuan Dinh-Xuan², Elin L. Reeves ${ }^{3}$, Matthew G. Broadhead ${ }^{3}$ \\ and Neil J. Bullen ${ }^{3}$ \\ Affiliations: 'Service de Pneumologie, University Paris-Sud, Inserm U999, Assistance Publique Hôpitaux de \\ Paris, Hôpital Bicêtre, Le Kremlin-Bicêtre, France. ${ }^{2}$ Service de Physiologie, Paris Descartes University EA \\ 2511, Hôpital Cochin, Assistance Publique Hôpitaux de Paris, Paris, France. ${ }^{3}$ Publications Office, European \\ Respiratory Society, Sheffield, UK.
}

Correspondence: Marc Humbert, Service de Pneumologie, Hôpitaux Universitaires Paris-Sud, Assistance Publique Hôpitaux de Paris, 78 rue du Général Leclerc, 94270 Le Kremlin-Bicêtre, France.

E-mail: marc.humbertabct.aphp.fr

0

@ERSpublications

The ERS's flagship journal is making great headway

http://ow.ly/DRPyz

As the title suggests, this is the third New Year "ambition" editorial of the current 5-year European Respiratory Journal (ERJ) editorial cycle. As we approach the half-way point, it is time not only to look back at 2014, but also to take stock of what has been achieved in the past 2 years and to set the agenda for what is still to be done. We will review the objectives we set in the previous editorials $[1,2]$ and look at some of the exceptional articles published in 2014.

This editorial will be broader in scope than the previous two, looking not only at what the ERJ publishes, but also at how it publishes. The production and dissemination of the journal continues to develop, and we would like to highlight some exciting recent and forthcoming developments.

\section{The story so far}

At the beginning of 2013, the first of these editorials [1] set out some key aims for the ERJ. One of these was to significantly improve the journal's impact factor - a measure that remains important to both readers and authors. This entails a determined campaign to publish only the highest quality articles. As we explain later in this editorial, the signs are that the strategy is working.

Also in that first editorial, the beginnings of a plan to introduce new sections to the journal were outlined, with "From the Museum" and "Lungstorming" among the mooted options. By January 2014 [2], those ideas had been elaborated and expanded upon: From the Museum was about to launch (it did so in March), while "Lungstorming" had become Back to Basics, which launched in August. They were joined by European Lung Corner - which had already launched, in December 2013 - and State of the Art, which arrived in September 2014.

\section{Submissions, peer review and speed}

At the time of writing, 2014 was on course to be a record year for ERJ submissions, surpassing the 2286 set in 2013 (fig. 1). We think the number of submissions is a major indicator of the esteem in which the journal is held, so we are very much encouraged by this continued growth in the number of authors who want to publish with us. To help authors further, we have reviewed and simplified our instructions for authors. They now focus more on the content of articles than on matters of style and formatting: in other words, we ask for what the journal needs, rather than what it would merely like. On top of this, the ERJ is adapting to help authors meet their funder mandates. "Green" (e.g. author self-archiving) and "gold"

Received: Oct 312014 | Accepted: Oct 312014

Conflict of interest: E.L. Reeves, M.G. Broadhead and N.J. Bullen are employees of the European Respiratory Society, other disclosures can be found alongside the online version of this article at erj.ersjournals.com 


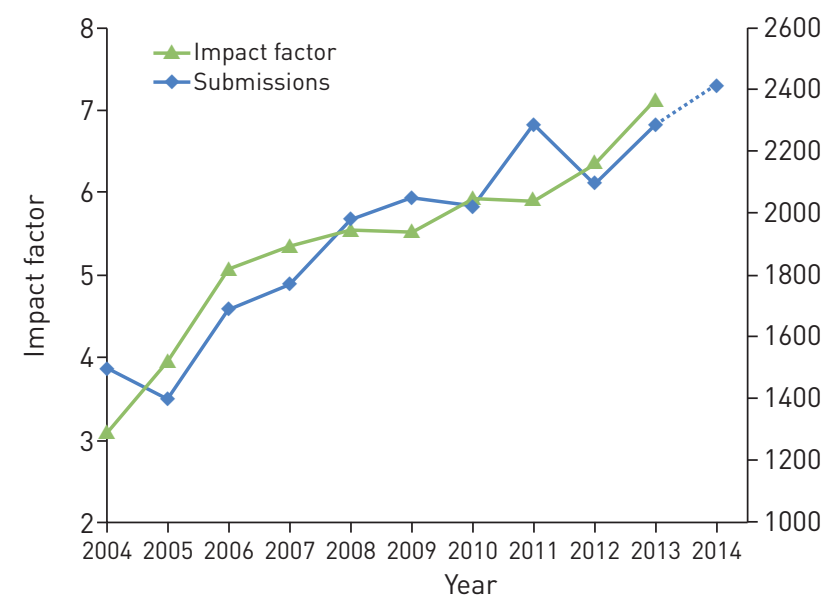

FIGURE 1 The evolution of the European Respiratory Journal impact factor (left axis) and submissions (right axis) over the past 10 years.

(e.g. publication under a creative commons licence) open access are both supported, and the ERS publications office is always ready to discuss any specific requirements your funder may have.

The increase in submissions has meant the rejection rate has also climbed. Although this high acceptance threshold means that sometimes we have to reject high-quality science, it allows us to distill out the very best submissions. We have also tried to help authors to publish by fulfilling two more of the ambitions set out in 2013 [1]: increasing the number of research letters published (as part of the new Agora section) and offering some authors the opportunity to resubmit to the European Respiratory Review. On a larger scale, the European Respiratory Society (ERS) is responding to the great demand from authors for an additional publishing outlet, and is in the process of launching ERJ Open Research, a new addition to the ERS publications family.

The Associate Editors, assisted by an army of reviewers, have also been working hard to ensure that authors receive prompt decisions on their manuscripts. We do not believe it is fair for authors to have to wait for months to receive a verdict. There will always be outliers, where it is difficult to find a reviewer, or where there is no consensus among reviewers, but we are proud of our turnaround times. In the first 11 months of 2014, our mean time to first decision was 20 days (median 15 days). This is coupled with the fact that a manuscript can be copy-edited, typeset and published online "in press" as little as 3-4 weeks after acceptance. We also aim to provide feedback to every author about their manuscript, whether it is accepted for publication or not.

\section{Some sparkling débuts...}

From the Museum, under the stewardship of Tom Kotsimbos (Monash University, Australia), has explored 500 years of revolutionary European art, discussing how developments in visual arts reflect wider changes in ways of thinking, across all disciplines $[3,4]$. From the Museum has brought a refreshing new aspect to the journal (fig. 2).

Back to Basics, with Melanie Königshoff (Ludwig Maximilians University Munich, Germany) at the helm, aims to improve the integration of basic science into the ERJ, bringing together translational reviews, conference reports and editorials, and helping to educate our clinical readers in the science underpinning their medicine, both now and in the future [5]. The first three Back to Basics reviews covered subjects as diverse as EGFR signalling [6], medical nanoparticles [7] and the latest advances in our knowledge of CFTR dysfunction [8]. This is an exciting new feature, and we look forward to watching it develop.

State of the Art, curated by Jeff Drazen (Harvard Medical School, USA and Editor-in-Chief of the New England Journal of Medicine) and Leo Fabbri (Università degli Studi di Modena e Reggio Emilia, Italy), is a major new initiative, and these invited review articles are written by very senior figures in the field. The series aims to provide, in the words of its curators, "an authoritative and evidence-based overview and discussion of recent and current studies/practices in a particular area of respiratory medicine". Although clinically focused, the reviews also provide extensive coverage of the basic science underlying their subject. State of the Art opened with a series on "Ageing, multimorbidity and the lung" [9-12] - a subject that will increasingly challenge all clinicians in the coming decades - and will broaden out to tackle many other pressing issues in respiratory medicine. 

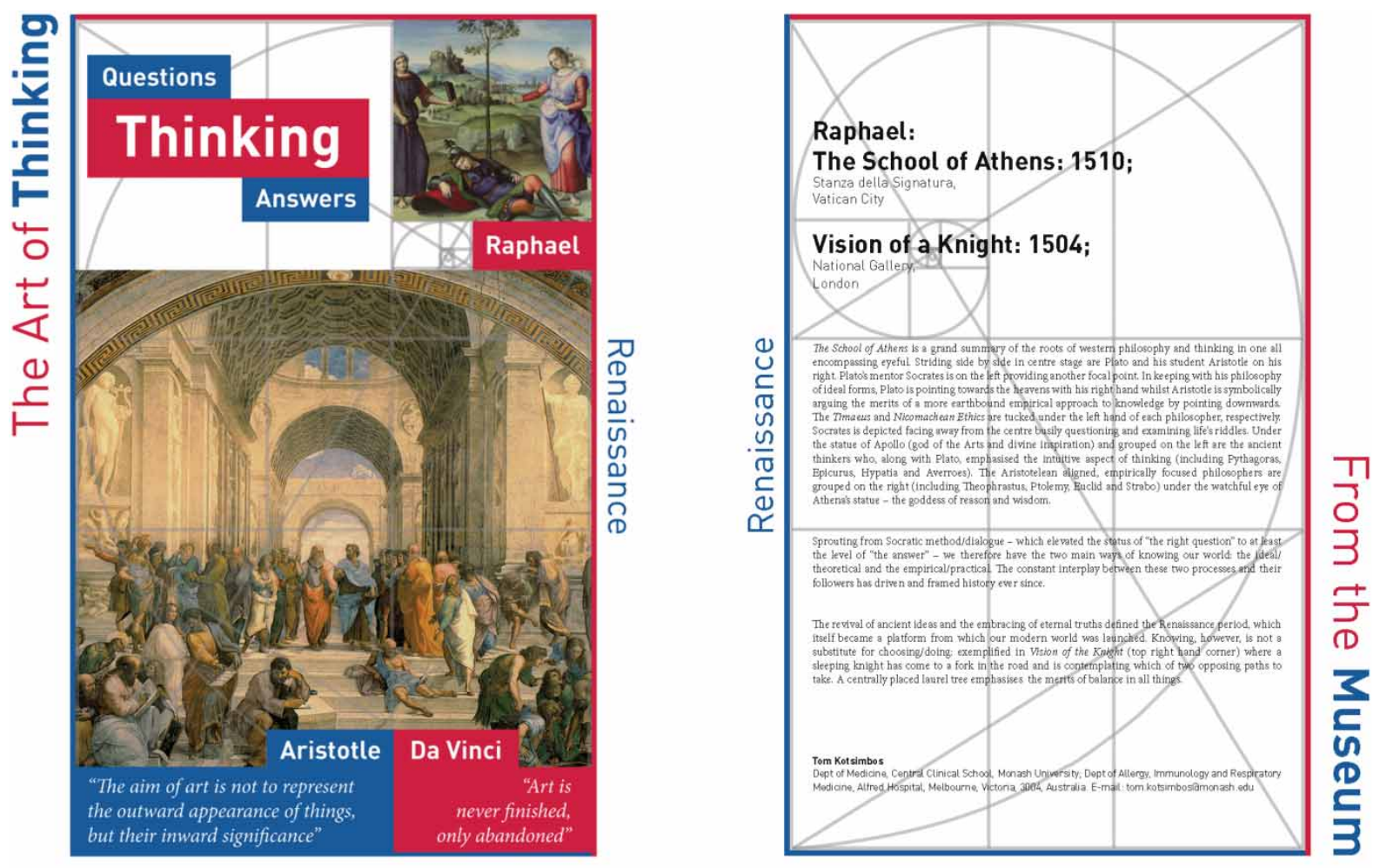

FIGURE 2 The first From the Museum article [4].

....and some star performances

In addition to the new sections, the ERJ published many other substantial contributions to the respiratory field in 2014. In February, we published the ERS/American Thoracic Society (ATS) guidelines on definition, evaluation and treatment of severe asthma [13], an extremely valuable document whose many merits are set out in an accompanying editorial by ERS Guidelines Director Guy Brusselle [14]. In November, the ERS Task Force on Cough Hypersensitivity Syndrome published a document affirming the validity and utility of the concept of cough hypersensitivity syndrome, which will no doubt form the basis of many further studies into chronic cough [15], and in time will lead to better management of this neglected condition.

In December, the ERS and ATS once again united to produce a Task Force report, this time a detailed technical standard for field walking tests in chronic respiratory disease [16], underpinned and accompanied by a systematic review of the existing literature [17]. The activities and dissemination of such Task Forces are vitally important to the respiratory community and represent a huge collaborative effort.

Original research is a major priority of our Journal, and the rock on which it is founded. In 2014 more than 200 original articles were published in the ERJ: we were proud to release exciting novel information covering the whole spectrum of respiratory medicine, including epidemiology [18], COPD [19-21], asthma $[22,23]$, paediatric pulmonology and cystic fibrosis [24, 25], tuberculosis and respiratory infections [26, 27], sleep medicine [28], pulmonary vascular medicine [29, 30], interstitial lung diseases [31], lung function [32] and lung cancer [33].

\section{Healthy competition}

The ERJ's impact factor jumped by more than three-quarters of a point this year. We now stand at 7.125, a new record for the journal (fig. 1). We are fourth in the Respiratory System category, a few hundredths of a point behind CHEST, which overtook us this year. Contrary to what you might think, we welcome this: competition among the leading journals reflects the dynamism in respiratory research, and we congratulate our friends at CHEST on their success. Respiratory publishing has a very collegiate spirit - indeed, the respiratory journal editors meet twice a year as a group to discuss developments in the field. 
We are confident that the ERJ's impact factor will continue to rise over the next few years, reflecting our strict focus on quality and relevance.

\section{A message about the medium}

The ERJ may project an image of calm and continuity, but below the surface it is constantly evolving. Although the journal continues to offer high-quality traditional services to authors, including full figure redrawing and copy-editing, this is coupled with a very modern approach to publishing, which recognises that the vast majority of readers now look at the ERJ online, rather than in print. Those readers find their way to us through an ever-growing number of routes: as well as Google, PubMed and our email table of contents, Wikipedia and Twitter are among the top 20 sources of visitors to the website.

The website has continued to develop. Following a full redesign of the article PDFs in 2013, enabling them to be more readable on screen, in 2014 we decided to upgrade the "in press" service to include typeset PDF articles. We are now also adding the full web versions of these articles. Further ongoing improvements to the site include a feature that will allow us to create "mini sites" to highlight topical issues. There is a new way to read articles, too: we are testing Lens, which has been developed by our colleagues at eLife and HighWire Press. Lens allows you to look at the figures, tables and references of a paper alongside the text. It may not sound like much, but it makes a real difference - it may even stop you printing the PDF! Finally, we cannot mention the website without mentioning the ERJ podcast, which has now been running for 4 years, and which provides an enjoyable opportunity to hear a leader in the field discuss the latest research.

The ERS publications have also moved into the world of social media, the source of an increasing proportion of online traffic. ERJ articles are publicised on Twitter and Facebook, as well as LinkedIn and even Sina Weibo. We have produced an authors' guide to using social media to gain exposure and feedback for their work (see www.ersjournals.com/site/authors/socialmedia.xhtml), and in 2015 we will upgrade the "suggested tweet" functionality so it works on all types of article. (We are pleased to be able to say that with this feature we were ahead of JAMA and the Los Angeles Times, both of which now offer suggested tweets.) Like many of our readers, we are still learning about how best to use social media [34]. We have also begun publicly tracking the social impact of individual articles using Altmetric (fig. 3) and online usage statistics.

The ERJ is keeping up with the growing trend in publishing to link and track everything about manuscripts and their authors, using standard identifiers. Our manuscript submission service now offers you the opportunity to add your ORCID identifier to your account. ORCID (http://orcid.org) is a disambiguation tool that allows you to track your publications across multiple outlets, and we expect its

\section{Article level metrics}

European Respiratory Journal is experimenting with article level metrics as a way to measure the social impact of scholarly il

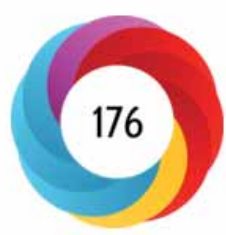

Score in context

Is one of the highest ever soores in this journal (ranked $\# 1$ of 1.305 ) show more.

Mentioned by

20 news outlets 10 news

2 Google+ users

Readers on

3 Mendele

0 CiteULike

Track this article

- Get email updates whe

this article is shared

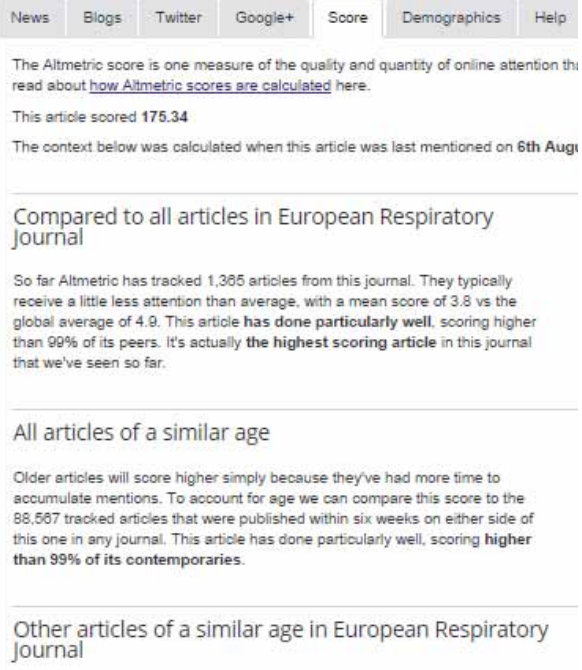

So far Altmetric has tracked 1,365 articles from this journal. They typically receive a little less attention than average, with a mean score of $3.8 \mathrm{vs}$ the global aversge of 4. 9 . This articie has done particularly well, scoring highe that we've seen 50 far.

\section{All articles of a similar age}

Older articles will score higher simply because theyve had more time to accumulate mentions. To sccount for age we can compare this score to the 88.507 tracked artices that were pubished within six weeks on ether side of this one in any journal. This artide has done particularly well, scoring higher

Other articles of a similar age in European Respiratory Journal

We're also able to compare this article to 25 articles from the same journal and published within six weeks on either side of this one. This article has done

very well, scoring higher than $90 \%$ of its contemporaries.
FIGURE 3 The Altmetric report for a 2014 European Respiratory Journal article [22]. 
use to grow in the coming years. We have also begun collecting funding information in a much more structured way, and have joined the FundRef scheme, a new industry standard that allows funders to trace the published output of their funding. Thirdly, we have implemented CrossMark. You may have noticed the logo appearing on the online versions of articles and the PDFs: these logos act as a web link, allowing you to find out whether you are reading the most recent version of the article, and whether any corrections have been published. Given that many of us download and keep articles, this could be a very useful tool. Looking further forward, it is possible that the concept of the "article" may one day become something much more fluid, and that we will really need something like CrossMark to keep track of it.

\section{Onward, upward and outward}

In 2015, we hope to see more of the same... but even better. We will continue to solicit and publish the very best original research, Task Force reports, guidelines, reviews and more. We will encourage discussion, providing a forum through insightful - and perhaps provocative - editorials, along with article-related correspondence. We will also launch new series, some of which are already being planned but some of which will come from new ideas generated during the year: if you have a concept for a series, or you think there is an area of respiratory science or medicine that needs authoritative, in-depth coverage, please let us know.

The ERJ will continue to stay abreast of wider developments affecting the scientific publishing field. Open access continues to be a hot topic, driven primarily by governments and funding agencies but also by people from all walks of life, inside and outside science. The ERS monitors the debate, and is constantly reviewing its publishing activities to ensure they are sustainable and equitable. Another key area of change in the research world centres on transparency and data sharing. At the time of writing, the European Medicines Agency had just released its "Policy on publication of clinical data for medicinal products for human use" [35], which comes into effect on January 1, 2015. Although there have been criticisms of the policy [36], it is an encouraging move towards greater openness. There are other straws in the wind, too: both PLOS and the BMJ now strongly, and sometimes controversially, encourage authors to share their data, and the Institute of Medicine in the USA is drafting a report on sharing of clinical trial data. We await it eagerly, and it will no doubt provoke heated debate!

\section{All hands on deck}

In summary, 2014 has been a very good year for the ERJ, and 2015 promises to be another one. With the strong backing of the ERS and its new Publications Committee Chairman, John Gibson, along with our colleagues at the other ERS publications, we are sailing forward carefully but confidently.

Many people contribute to the success of the ERJ: the Associate Editors, advisory and editorial boards, reviewers (you can see a list of 2014 reviewers on the website) and staff, but above all the authors who submit their lovingly crafted work and the readers who use that work to drive further progress in respiratory medicine. Thank you, all of you.

\section{References}

Humbert M. The ambition of the European Respiratory Journal. Eur Respir J 2013; 41: 1-2.

Humbert M. The ambition of the European Respiratory Journal: chapter 2. Eur Respir J 2014; 43: 1-2.

Kotsimbos T. From the Museum: the Art of Thinking. Eur Respir J 2014; 43: 700-701.

Kotsimbos T. From the Museum: the Art of Thinking. Part One: Thinking. Eur Respir J 2014; 43: $702-703$.

Königshoff M. The new Back to Basics section: emerging concepts in basic and translational medicine. Eur Respir J 2014; 44: 297-298.

6 Vallath S, Hynds RE, Succony L, et al. Targeting EGFR signalling in chronic lung disease: therapeutic challenges and opportunities. Eur Respir J 2014; 44: 513-522.

7 van Rijt SH, Bein T, Meiners S. Medical nanoparticles for next generation drug delivery to the lungs. Eur Respir J 2014; 44: 765-774.

8 Mall MA, Hartl D. CFTR: cystic fibrosis and beyond. Eur Respir J 2014; 44: 1042-1054.

9 Drazen JM, Fabbri LM. Ageing and multimorbidity. Eur Respir J 2014; 44: 557.

10 Faner R, Cruz T, López-Giraldo A, et al. Network medicine, multimorbidity and the lung in the elderly. Eur Respir J 2014; 44: 775-788.

11 Divo MJ, Martinez CH, Mannino DM. Ageing and the epidemiology of multimorbidity. Eur Respir J 2014; 44: 1055-1068.

12 MacNee W, Rabinovich RA, Choudhury G. Ageing and the border between health and disease. Eur Respir J 2014; 44: $1332-1352$.

13 Chung KF, Wenzel SE, Brozek JL, et al. International ERS/ATS guidelines on definition, evaluation and treatment of severe asthma. Eur Respir J 2014; 43: 343-373.

14 Brusselle GG, Kraft M. Trustworthy guidelines on severe asthma thanks to the ERS and ATS. Eur Respir J 2014; 43: $315-318$.

15 Morice AH, Millqvist E, Belvisi MG, et al. Expert opinion on the cough hypersensitivity syndrome in respiratory medicine. Eur Respir J 2014; 44: 1132-1148.

16 Holland AE, Spruit MA, Troosters T, et al. An official European Respiratory Society/American Thoracic Society Technical Standard: field walking tests in chronic respiratory disease. Eur Respir J 2014; 44: 1428-1446. 
Singh SJ, Puhan MA, Andrianopoulos V, et al. An official systematic review of the European Respiratory Society/ American Thoracic Society: measurement properties of field walking tests in chronic respiratory disease. Eur Respir J 2014; 44: 1447-1478.

18 Schikowski T, Adam M, Marcon A, et al. Association of ambient air pollution with the prevalence and incidence of COPD. Eur Respir J 2014; 44: 614-626.

19 Suissa S, Dell'Aniello S, Suissa D, et al. Friday and weekend hospital stays: effects on mortality. Eur Respir J 2014; 44: 627-633.

20 Vozoris NT, Fischer HD, Wang X, et al. Benzodiazepine drug use and adverse respiratory outcomes among older adults with COPD. Eur Respir J 2014; 44: 332-340.

21 Abroug F, Ouanes-Besbes L, Fkih-Hassen M, et al. Prednisone in COPD exacerbation requiring ventilatory support: an open-label randomised evaluation. Eur Respir J 2014; 43: 717-724.

22 Gade EJ, Thomsen SF, Lindenberg S, et al. Asthma affects time to pregnancy and fertility: a register-based twin study. Eur Respir J 2014; 43: 1077-1085.

23 O'Byrne PM, Bleecker ER, Bateman ED, et al. Once-daily fluticasone furoate alone or combined with vilanterol in persistent asthma. Eur Respir J 2014; 43: 773-782.

24 Teunissen J, Hochs AHJ, Vaessen-Verberne A, et al. The effect of $3 \%$ and $6 \%$ hypertonic saline in viral bronchiolitis: a randomised controlled trial. Eur Respir J 2014; 44: 913-921.

25 Smith DJ, Badrick AC, Zakrzewski M, et al. Pyrosequencing reveals transient cystic fibrosis lung microbiome changes with intravenous antibiotics. Eur Respir J 2014; 44: 922-930.

26 Diel R, Vandeputte J, de Vries G, et al. Costs of tuberculosis disease in the European Union: a systematic analysis and cost calculation. Eur Respir J 2014; 43: 554-565.

27 Lange C, Abubakar I, Alffenaar JW, et al. Management of patients with multidrug-resistant/extensively drug-resistant tuberculosis in Europe: a TBNET consensus statement. Eur Respir J 2014; 44: $23-63$.

28 Kend BD, Grote L, Bonsignore MR, et al. Sleep apnoea severity independently predicts glycaemic health in nondiabetic subjects: the ESADA study. Eur Respir J 2014; 44: 130-139.

29 Sitbon O, Jaïs X, Savale L, et al. Upfront triple combination therapy in pulmonary arterial hypertension: a pilot study. Eur Respir J 2014; 43: 1691-1697.

30 Becattini C, Agnelli G, Germini F, et al. Computed tomography to assess risk of death in acute pulmonary embolism: a meta-analysis. Eur Respir J 2014; 43: 1678-1690.

31 Silhan LL, Shah PD, Chambers DC, et al. Lung transplantation in telomerase mutation carriers with pulmonary fibrosis. Eur Respir J 2014; 44: 178-187.

32 Quanjer PH, Capderou A, Mazicioglu MM, et al. All-age relationship between arm span and height in different ethnic groups. Eur Respir J 2014; 44: 905-912.

33 Campos-Parra AD, Avilés A, Contreras-Reyes S, et al. Relevance of the novel IASLC/ATS/ERS classification of lung adenocarcinoma in advanced disease. Eur Respir J 2014; 43: 1439-1447.

34 Van Noorden R. Online collaboration: scientists and the social network. Nature 2014; 512: 126-129.

35 European Medicines Agency. European Medicines Agency policy on publication of clinical data for medicinal products for human use. EMA/240810/2013. www.ema.europa.eu/docs/en_GB/document_library/Other/2014/10/ WC500174796.pdf Date last updated: October 2, 2014. Date last accessed: October 14, 2014.

36 Jefferson T. EMA's release of regulatory data-trust but verify. http://blogs.bmj.com/bmj/2014/10/07/ tom-jefferson-emas-release-of-regulatory-data-trust-but-verify Date last updated: October 7, 2014. Date last accessed: October 14, 2014. 